\title{
SIGNIFICADOS QUE OS PROFISSIONAIS DE ENFERMAGEM ATRIBUEM AO CUIDADO DE CRIANÇAS INSTITUCIONALIZADAS COM AIDS
}

\author{
Hilda Maria Barbosa de Freitas ${ }^{1}$, Dirce Stein Backes², Adriana Dall' Asta Pereira ${ }^{3}$, Carla Lizandra de Lima \\ Ferreira ${ }^{4}$, Mara Regina Caino Marchiori ${ }^{5}$, Martha H. Teixeira de Souza ${ }^{6}$, Alacoque Lorenzini Erdmann ${ }^{7}$
}

\footnotetext{
${ }^{1}$ Mestre em Enfermagem. Docente do Departamento de Enfermagem do Centro Universitário Franciscano (UNIFRA). Rio Grande do Sul, Brasil. E-mail: hildasame@gmail.com

${ }^{2}$ Doutora em Filosofia da Enfermagem. Docente do Departamento de Enfermagem da UNIFRA. Rio Grande do Sul, Brasil. E-mail: backesdirce@ig.com.br

${ }^{3}$ Mestre em Enfermagem. Docente do Departamento de Enfermagem da UNIFRA. Membro do GEPESES. Rio Grande do Sul, Brasil. E-mail: adrianadap@terra.com.br

${ }^{4}$ Mestre em Enfermagem. Docente do Departamento de Enfermagem da UNIFRA. Rio Grande do Sul, Brasil. E-mail: carlafer@ terra.com.br

${ }^{5}$ Mestre em Enfermagem. Docente do Departamento de Enfermagem da UNIFRA. Rio Grande do Sul, Brasil. E-mail: maramarc@ hotmail.com

${ }^{6}$ Mestre em Enfermagem. Docente do Departamento de Enfermagem da UNIFRA. Rio Grande do Sul, Brasil E-mail: marthats@ terra.com.br

${ }^{7}$ Doutora em Enfermagem. Professora Titular do Departamento de Enfermagem e do Programa de Pós-Graduação em Enfermagem da Universidade Federal de Santa Catarina. Pesquisadora CNPq. Santa Catarina, Brasil. E-mail: alacoque@ newsite.com.br
}

\begin{abstract}
RESUMO: Objetivou-se compreender o significado que os profissionais de enfermagem atribuem ao cuidado de crianças com aids institucionalizadas. Trata-se de uma pesquisa qualitativo-exploratória. Os dados foram coletados entre abril e junho de 2007, por meio de entrevista com seis profissionais de enfermagem que atuam em uma instituição que abriga crianças com aids, localizada na região central do Rio Grande do Sul. O significado das falas codificadas resultou em dois temas convergentes: vivenciando o cuidado de ser mãe e/ ou cuidador; compreendendo a aids como possibilidade interativa. Os resultados evidenciaram que, mesmo diante de um aparente fracasso ou desordem, os profissionais de enfermagem, na condição de cuidadores do indivíduo como um ser integral, são capazes de auxiliar e facilitar o processo adaptativo e o viver saudável da criança institucionalizada com aids. Conclui-se, que compreender o significado de ser cuidador de criança com aids implica em acolher a experiência singular que integra o processo saúde-doença.
\end{abstract}

DESCRITORES: Enfermagem pediátrica. Cuidado da criança. Sorodiagnóstico da aids.

\section{MEANINGS OF CARING FOR HIV/AIDS INSTITUTIONALIZED CHILDREN ATTRIBUTED BY NURSING PROFESSIONALS}

\begin{abstract}
This paper aimed to better understand the meaning of caring for HIV/AIDS institutionalized children attributed by nursing professionals. It is an exploratory, qualitative study. The data was collected from April to June, 2007 through interviewing six nursing professionals who work at an institution housing HIV/AIDS children in southern Brazil. The meanings of the coded speech resulted in two convergent themes: experiencing the role of being mother or caregiver; understanding AIDS as an interactive possibility. The findings showed that even in the face of apparent failure or disorder, nursing professionals in the condition of caregivers of individuals as integral people are able to help and to facilitate de adaptation process and healthy living of institutionalized HIV/AIDS children. The study concluded that understanding the meaning of being a caregiver to a child with AIDS implies embracing the unique experience that integrates the health-disease process.
\end{abstract}

DESCRIPTORS: Pediatric nursing. Child care. Diagnosis of SIDA.

\section{EL SIGNIFICADO QUE LOS PROFESIONALES DE ENFERMERÍA LE ATRIBUYEN AL CUIDADO DE NIÑOS INSTITUCIONALIZADOS CON SIDA}

\begin{abstract}
RESUMEN: El estudio tuvo como objetivo comprender el significado que los profesionales de enfermería le atribuyen al cuidado de niños institucionalizados con SIDA. Se trata de una investigación cualitativa y exploratoria. La recolección de los datos se hizo entre abril y junio de 2007, por medio de entrevistas con seis profesionales de enfermería que trabajan en una institución que alberga niños con SIDA, situada en la región central de Rio Grande do Sul, Brazil. El significado de las respuestas codificadas dio lugar a dos temas convergentes: vivir el rol de ser madre y/o cuidador; comprender el SIDA como posibilidad interactiva. Los resultados mostraron que incluso ante un aparente fracaso o desorden, los profesionales de enfermería, en la condición de cuidadores del individuo como un ser integral, son capaces de auxiliar y facilitar el proceso de adaptación y ofrecer una vida saludable al niño institucionalizado con SIDA. Se concluye que la comprensión del significado de ser un cuidador de un niño con SIDA consiste en acoger la experiencia única que integra el proceso salud-enfermedad.
\end{abstract}

DESCRIPTORES: Enfermería pediátrica. Cuidado de niños. Diagnostico de SIDA. 


\section{INTRODUÇÃO}

Sabe-se que a infância é uma fase do ciclo vital em que a criança passa por vários processos de aprendizagem, bem como novas e contínuas adaptações. Através do seu mundo objetivo e abstrato, a criança é capaz de materializar e, ao mesmo tempo, fantasiar sobre o que experiência. Se expressa comumente por meio de ações, gestos, atitudes e/ou pelos mais diferentes comportamentos aceitáveis e inaceitáveis.

A criança é um ser biológico e simbólico em construção e adaptação ao meio em que está inserida. Os pais são os responsáveis pela estrutura emocional da criança, desempenhando o papel de facilitadores no seu processo de crescimento e desenvolvimento. As condições ambientais do micro e macrossistema em que vive a criança e a estrutura familiar em que ela está inserida são aspectos significativos no desenvolvimento de suas potencialidades como ser-no-mundo. ${ }^{1}$

O processo de crescimento e de desenvolvimento esperado, assim como as expectativas de vida da criança são alterados com o advento de uma situação adversa, como, por exemplo, a aids, a qual é caracterizada como doença que se manifesta após a infecção do organismo humano pelo Vírus da Imunodeficiência Humana (HIV). ${ }^{2}$

A epidemia de aids se constitui em um desafio para a saúde global. O HIV já causou cerca de 25 milhões de mortes e provocou profundas mudanças demográficas, econômicas e sociais na maioria dos países mais afetados. Estima-se que, a cada dia, cerca de 6.800 pessoas são infectadas pelo HIV e 5.700 morrem, em decorrência da doença, em todo o mundo. Os jovens entre 15-24 anos representam $45 \%$ das novas infecções no mundo inteiro. Em âmbito global, o número de jovens que convivem com HIV aumentou de 1,6 milhões, em 2001, para 2 milhões, em 2007. Estima-se que 370 mil crianças menores de 15 anos se infectaram pelo HIV em 2007. ${ }^{3}$

A aids pediátrica desenvolve-se de maneira distinta na criança quando comparada à do adulto portador, uma vez que a criança apresenta um sistema imunológico ainda em formação. Sabe-se, também, que as crianças podem adquirir o HIV da mesma maneira que os adultos, porém, as formas de transmissão e respectivas proporções são diferenciadas. ${ }^{3}$

Nesse sentido, as crianças infectadas pelo HIV, em especial aquelas por transmissão vertical, necessitam de acompanhamento contínuo pela dependência de tratamentos prolongados e intensivos. Logo, são crianças que podem ser enquadradas nos denominados grupos especiais, pelas necessidades singulares de cuidado.

Dentre as crianças com aids, muitas são cuidadas por familiares, outras são encaminhadas para instituições de apoio, devido às condições socioeconômicas precárias dos pais ou em consequência da orfandade. Estima-se que, atualmente, em todo mundo, cerca de 15 milhões de crianças já perderam um ou ambos os pais devido à aids. ${ }^{4}$ Esses dados são alarmantes e justificam a necessidade de estudos voltados à esta temática em questão.

Ser cuidador de uma criança com aids, nessas condições, implica no desenvolvimento de habilidades humano-interativas, capazes de compreender a criança portadora da doença como um ser único e envolvido em um processo amplo e interativo; implica no desenvolvimento de novos processos adaptativos para cuidar de forma integral e complexa, conforme asseguram os estudiosos do pensamento complexo..$^{5-6}$ Segundo eles, a ciência do passado pensou ter encontrado uma verdade simples, uma verdade determinista, uma verdade que reduz o universo a algumas fórmulas. Hoje, se sabe que o desafio do mundo e da realidade é a complexidade que cresce visivelmente nos diferentes contexto, s sociais.

Com base no exposto e face à doença, que vem crescendo e acometendo indivíduos das diferentes fases do ciclo vital, questionamo-nos enquanto cuidadores de enfermagem: que significado os profissionais de enfermagem atribuem ao cuidado às crianças com aids e institucionalizadas?

Ao responder ao questionamento anteriormente explicitado e, na expectativa de possibilitar novos olhares acerca do cuidado em saúde/enfermagem, é preciso que os profissionais considerem a criança com aids não como um indivíduo doente, mas como um ser singular que possui infinitas possibilidades de viver saudável, independente de idade, sexo e/ou condição social. Assim, objetivou-se compreender o significado que os profissionais de enfermagem atribuem ao cuidado de crianças institucionalizadas com aids.

\section{METODOLOGIA}

Trata-se de um estudo qualitativo exploratório. A pesquisa qualitativa, diferentemente dos métodos quantitativos, não busca enumerar ou 
medir eventos ou incidentes para a análise dos dados. Seu foco de interesse é a compreensão dos significados dos fenômenos na perspectiva dos participantes, de forma ampla e complexa. ${ }^{7}$

Os dados foram coletados entre abril e junho de 2007, com cuidadores, mais especificamente, com seis técnicos de enfermagem que atuam em uma instituição de caráter não governamental que abriga unicamente crianças com HIV/aids (de zero a 12 anos), muitas delas órfãos de pai e mãe. Salienta-se, que além das seis técnicos de enfermagem, a instituição possui também uma enfermeira, responsável técnica, a qual não foi entrevistada por estar envolvida em outras funções administrativas da instituição.

A instituição localiza-se na região central do Rio Grande do Sul. Os cuidadores de enfermagem selecionados foram os que possuíam um vínculo direto com as crianças e que responderam afirmativamente ao convite formal. A instituição, além de abrigar crianças com aids, realiza um trabalho social educativo com as famílias envolvidas nessa problemática, no sentido de orientá-las quanto à doença e suas repercussões no contexto social.

Os dados foram coletados por meio de entrevista semiestruturada, a qual foi áudio-gravada por autoras do trabalho e a seguir transcrita, sendo que cada entrevista durou em média trinta e quarenta minutos. Cada profissional entrevistado foi valorizado como ser uno e singular, com sua história de vida, estabelecendo-se um vínculo de respeito e confiança, com troca de experiências por meio das vivências e do diálogo, sendo que os dados foram saturados com as seis entrevistas a partir da questão norteadora: "Que significado você atribui ao cuidado de enfermagem de uma criança com aids, aqui na instituição de apoio"?

A análise dos dados foi conduzida pelo olhar da complexidade. Pensar nos conceitos, sem dá-los por concluídos e compreender a multidimensionalidade dos fenômenos, a partir da singularidade e das possíveis interações, relações e associações, foi o caminho escolhido para este estudo. ${ }^{5-6}$ Desse modo, os dados foram organizados com base nos pressupostos da análise temática, ${ }^{8}$ a qual possibilitou a identificação das principais percepções dos entrevistados, a identificação das categorias de análise, bem como, a interpretação das mesmas a partir da vivencia das pesquisadoras com a temática em questão.

O significado das falas codificadas e analisadas resultou em dois temas convergentes, quais sejam: vivenciando o cuidado de ser mãe e/ou cuidador; compreendendo a aids como possibilidade interativa.

Para o desenvolvimento da pesquisa, foram observados os aspectos éticos, conforme Resolução $\mathrm{n}^{\circ}$. 196, de 10 de outubro de 1996, que define as diretrizes e normas reguladoras de pesquisas envolvendo seres humanos. ${ }^{9}$ Foi solicitado o Termo de Autorização da Instituição para a realização do estudo e o Termo de Consentimento Livre e Esclarecido a cada profissional que aceitou participar da pesquisa. Para assegurar o anonimato, os participantes foram identificados com a letra " $\mathrm{C}$ ", seguida por um número, correspondente à fala.

O projeto de pesquisa foi aprovado pelo Comitê de Ética em Pesquisa do Centro Universitário Franciscano - UNIFRA, sob o $\mathrm{n}^{\mathrm{o}}$ 247.2008.2.

\section{RESULTADOS}

Dos seis cuidadores entrevistados, quatro são mães, com idade entre vinte quatro a quarenta e dois anos, e as outras duas, solteiras, e ambas com vinte três anos. Todas trabalhavam na instituição há mais de dois anos, com apenas um vínculo empregatício. Sentiam-se realizadas e comprometidas com o cuidado das crianças na instituição, bem como, envolvidas com os seus familiares.

\section{Vivenciando o cuidado de ser mãe e/ou cuidadora}

Para as cuidadoras de enfermagem que atuam no cuidado de crianças institucionalizadas com aids, o processo, inicialmente, se mostrou confuso, conflituoso, pelo fato de a criança estar numa situação de fragilidade e vulnerabilidade, longe de seu significante familiar, o que contribui para o afloramento de sentimentos de perda, abandono e outros.

Os cuidadores de enfermagem vivenciam, frequentemente, o conflito: "preciso ser mãe, preciso ser cuidadora ou necessito ser mãe e cuidadora?" Este conflito de sentimentos fica expresso nas falas a seguir:

[...] às vezes sinto-me a segunda mãe, faço tudo que uma mãe faria, dando carinho e atenção, pois nossa tarefa não é exclusivamente o cuidado técnico. Sei que somos a referência deles enquanto estão no Lar (C1).

[...] eu amo trabalhar com eles. Por vezes não sei se me sinto mãe ou profissional... vejo o quanto eles sofrem com a distância da família... (C2).

[...] não me sinto técnica, mas uma espécie de mãe. No momento que estou com eles sei que dependem de 
mim, e eu tenho o compromisso de ajudar para que se tornem alguém na vida... (C3).

[...] cuido deles como se fossem da minha família... tenho um grande carinho por eles...adoro crianças (C4)

[...] bom, não me vejo como técnica e sim como mãe. A gente se sente mãe porque pode chamar a atenção deles, ensinar e educar (C6).

Os dados evidenciam que, enquanto cuidadoras, mães, mulheres e profissionais, cuidar de crianças com aids é gratificante e enriquecedor, na medida em que as profissionais conseguem transcender a compreensão tecnicista - do ser profissional. Sentem-se comprometidas com o ser profissional e não somente com o fazer profissional. Salientam que os seus problemas são pequenos quando comparados aos da criança com aids, que se encontra numa situação, aos olhos cientificizados e seguros, "anormal e insustentável", pelo fato de estarem longe do convívio dos pais e significantes, os quais julgam essenciais no convívio, principalmente nesta fase.

Além dos sentimentos de conforto e proteção, as cuidadoras de enfermagem experienciaram também, situações adversas e contraditórias, visto que necessitam adaptar-se e direcionar o cuidado à singularidade de cada criança. Este processo é facilitado por meio do diálogo, da empatia e da formação de vínculos de confiança.

\section{Compreendendo a aids como possibilidade interativa}

O processo de cuidado institucionalizado ocorre, mediante um evento inesperado ou, até mesmo, inexplicável, de desorganização e caos. Este acaso ou ocaso é inesperado para o indivíduo e a família que experienciam o processo da doença. Também o é para os profissionais, que precisam encontrar estratégias para lidar com complexidade em que se encontram envolvidos e para a qual são desafiados.

As falas, a seguir, refletem o significado de estar e fazer parte de um processo contraditório, mas, ao mesmo tempo, gratificante e impulsionador de novas possibilidades interativas.

É gratificante... eu gosto do que faço. Me sinto bem em poder cuidar, dar apoio, estar dando mais qualidade e tempo de vida. Poder cuidar deles nesse momento que estão longe de seus pais é muito importante, pois deve ser difícil para eles estar morando aqui... (C1).

Às vezes paro e fico pensando o quanto o meu trabalho com eles mudou minha vida, sou muito feliz por estar aqui juntinho deles, fico triste também por eles estarem em uma instituição, muitos sem pais. Me coloco no lugar deles e não é nada fácil, pois dói meu coração... a gente começa a ter novos olhares (C2).

Caí aqui para trabalhar por acaso, e agora não me vejo em outro serviço, adoro cuidar de crianças, no início não foi nada fácil, achava que não ia conseguir dar atenção que elas precisam...mas depois fui compreendendo que são crianças como qualquer outra e estou aprendendo muito com elas (C4).

Me sinto gratificada por estar dedicando parte de minha vida a crianças tão especiais. No início, quando comecei a trabalhar aqui, achei que não fosse conseguir, eu chorava, tinha muita pena delas, tão pequenas e passando por tudo isso... aí a gente começa a cuidar diferente. Começa a ver as coisas com outros olhos. Sempre que posso levo um para passar of final de semana comigo (C5).

Ter uma doença crônica significa, para muitos, perderem a identidade social e a possibilidade de estabelecer ou criar interações. Contudo, para os cuidadores entrevistados a possibilidade de cuidar de crianças com aids, significa cuidar de crianças especiais, como seres humanos singulares, capazes de reinventar a sua história.

\section{DISCUSSÃO}

O cuidado de enfermagem, pelo olhar da complexidade, comporta a relação dialógica e complementar entre as noções de ordem, de desordem e de organização; comporta o princípio da incompletude e da incerteza, como processo que coopera para a geração de uma nova ordem existencial. A auto-organização, característica dos fenômenos vivos, exige permanente processo de desorganização, transformado em processo permanente de reorganização e de novas possibilidades interativas. ${ }^{5-6}$

Para estabelecer uma relação dialógica autêntica, que favoreça o vínculo de confiança com a criança portadora de aids, o cuidador de enfermagem precisa acolher e dialogar com a individualidade intersubjetiva, permitindo a expressão de sua singularidade e historicidade, sem medos, ressentimento ou dúvidas. ${ }^{10-11}$

O cuidador de enfermagem, para compreender a identidade e a complexidade da criança com aids, precisa, inicialmente, transcender a idéia ou foco de doença como um fim em si mesmo. A criança ou indivíduo com aids é, acima e antes de tudo, um ser humano, uno e autônomo, por isso capaz de fazer escolhas e organizar-se ou 
reorganizar-se, a partir das demandas em que implicam estas escolhas.

Nessa perspectiva, o cuidador de enfermagem precisa, gradativamente, se abrir para o pensamento da complexidade, o qual considera cada indivíduo como um ser autônomo, dotado de capacidades intelectuais e de liberdade de ação, diferente de um robô, que necessita ser programado. Importa perceber seu projeto com respeito à globalidade das variáveis que o constituem. Somente uma visão sistêmica responderá às suas aspirações, suas expectativas, suas vontades, sua história de vida, sua prática e papel social. ${ }^{5-6}$

É consenso de que doença, qualquer que seja ela, altera a rotina do ser criança, em condições que, do ponto de vista hegemônico do conceito de saúde, se constituiria em uma limitação para o viver saudável. Enquanto enfermeiros profissionais do cuidado, perguntamo-nos: que significado é atribuído ou deve ser atribuído ao cuidado de uma criança institucionalizada com aids, quando para a sociedade, trata-se de um indivíduo sem nome, sem condições e perspectivas de futuro? Como potencializar o viver saudável desta criança, mesmo sabendo que, provavelmente, será mais um indivíduo discriminado pela frieza dos que reduzem a saúde apenas à ausência de doenças?

Ser profissional da saúde e, principalmente, profissional do cuidado, nessas condições, significa alterar ou inverter a ordem estabelecida por verdades, historicamente consagradas como verdades absolutas e inquestionáveis, conforme nos pede o pensamento complexo: A complexidade comporta as contradições e as incertezas, a lógica clássica teve valor de verdade absoluta e geral, assim, ao chegar a uma contradição, o pensamento retrocedia, tendo a contradição como sinal de alarme indicador de erro. ${ }^{6}$

A criança portadora de aids é muito mais que um ser doente. Ela é expressão de vida, de dinamismo e de capacidades adaptativas e organizativas incalculáveis, que podem ser potencializadas para um viver saudável, mesmo em condição de doença. Este dinamismo e circularidade precisam, no entanto, fazer parte do cotidiano de quem se envolve no cuidado destes indivíduos. Isto, certamente, requer, por parte do profissional, mais criatividade, interatividade e iniciativa, para apreender as singularidades e ampliar a rede de relações e de associações, uma vez que eventos complexos requerem, também, intervenções amplas e complexas. ${ }^{12}$

Esse processo de cuidado deve desenvolver no profissional de enfermagem a capacidade de in- tegrar a ordem e a desordem, derivadas de mudanças de contexto, de ambiente e de outros fatores que fazem parte do processo do cotidiano da criança. É fundamental considerar que, além do cuidado que envolve a doença, as crianças necessitam, também, de internações, carinho, amor, empatia.

A criança, diante de uma condição de aparente desordem, precisa vivenciar sua infância por meio do brincar, do aprender, do viver, do sorrir, enfim, do estar presente, do participar, do compartilhar com o outro. Sendo assim, o cuidador dessa criança precisa compreender os aspectos individuais, considerando valores e culturas de cada uma, para considerar todas as suas dimensões e estimular suas capacidades, como ser singular e autônomo, com possibilidades de vir-a-ser, mais e melhor no ambiente em que se encontra. ${ }^{13}$

Mesmo diante do fato de estar vivenciando um evento "anormal" para a sociedade, as novas possibilidades interativas e associativas induzem a criança a construir e desconstruir, continuamente, ligações ou elos de ligação significativos. ${ }^{14}$ Tais elos podem representar perdas ou a possibilidade de uma nova organização, onde a criança consiga adaptar-se a doença, a qual necessita de cuidados contínuos e, em muitos momentos, de ficar afastada de seus familiares. Esse contexto precisa ser compreendido e acolhido pelos profissionais cuidadores, para que se constitua em um processo circular, dinâmico, motivador e facilitador do viver saudável desse ser em formação.

Em meio à desordem do cotidiano é importante que a rede de interações seja fortalecida e, gradativamente, ampliada pela acolhida do diferente, pelos vínculos de confiança, pela reciprocidade dialógica e pela capacidade de potencializar cada evento ou acontecimento como único. Esta conformação do ambiente permitirá à criança portadora de doença desenvolver-se como sujeito e autor da sua história. ${ }^{12}$

Para que a criança sinta-se segura em um ambiente desconhecido, os cuidadores de enfermagem necessitam realizar um cuidado vivo, autêntico, facilitado pelo princípio dialógico. ${ }^{14}$ Dessa forma, o cuidado precisa, além de dominar as técnicas prescritivas, possibilitar escolhas, para que a criança seja autora da sua história. Isto significa ser o cuidado a essência da enfermagem, assim como esta é a essência do cuidado circular, dinâmico, interativo, integral e integrador. ${ }^{15}$

Profissionais precisam considerar as tensões, conflitos e instabilidades que permeiam o cotidiano de quem se vê acometido por uma 
doença crônica. De outro modo, precisam também considerar, sobretudo, que tanto o portador quanto os familiares e significantes são capazes de, rapidamente, reorganizarem o seu cotidiano, adaptando-se e adequando-se às novas exigências imagináveis e inimagináveis.

Profissionais de enfermagem devem ser considerados mediadores no processo do cuidado de uma criança com aids, dando ênfase ao diálogo entre o cuidado formal e informal. Em especial, pela negociação contínua de ações estratégicas de cuidado, capazes de ampliar a rede de interações com os diferentes autores sociais. ${ }^{12}$

Por fim, é importante que profissionais considerem o indivíduo, seja ele portador de doença ou significante, como protagonista e autor da sua história. O que significa considerá-lo como alguém exposto a adaptações, conflitos, ou seja, ordem, incerteza, instabilidade e caos. Alguém, capaz de continuamente organizar-se e reorganizar-se, a partir das múltiplas interações, relações e associações familiares e sociais.

\section{CONSIDERAÇÕES FINAIS}

Muito além de trazer respostas prontas ou verdades inquestionáveis, o estudo se propôs a instigar novas possibilidades dialógicas e dialéticas, a partir do conhecimento já construído acerca da aids. Propôs-se, inicialmente, a compreender o significado do ser/estar/conviver com uma doença, capaz de conduzir a sentimentos de medo, angústia e perdas, tanto físicas quanto emocionais, sociais e relacionais, na inexistência de uma integração dos elementos provocadores de ordem e desordem.

Acredita-se que cuidado não pode ser apreendido como uma ação pontual ou linear. Deve, sobretudo, ser apreendido como um processo circular, dinâmico e gradual, que envolve o conflito ou a dúvida do cuidado que exercem. Ser mãe ou cuidadora de uma criança com aids evidencia-se como possibilidade de, em meio à desordem, ampliar as possibilidades interativas e associativas. Nesta perspectiva, os profissionais de enfermagem sentem-se gratificados pela possibilidade de atuarem com crianças que, além de uma terapêutica eficaz e eficiente, necessitam contar com pessoas interessadas em desenvolver habilidades relacionadas à empatia, dedicação, acolhida, diálogo com o diferente e cuidado integral.

Nos relatos das cuidadoras de enfermagem sobre o trabalho na instituição, o cuidado destacou-se como escolha de vida e fonte de realiza- ção. A integralidade do cuidado à criança esteve presente no processo de cuidado, visto que, para cuidar de um ser fragilizado e vulnerabilizado, é preciso ir além das habilidades técnicas e prescrições normativas.

Compreender e acolher o significado ou sentimento de ser cuidador de uma criança com aids significa acolher a experiência que se expressa de forma singular em cada um dos cuidadores que integram o processo de adoecimento. Sendo assim, o cuidado em saúde precisa ser amplo e contextualizado; precisa levar em conta a unicidade e a multidimensionalidade do ser cuidado precisa conviver com o paradoxo de estar vivo e, ao mesmo tempo, ser portador de uma doença crônica, precisa levar em conta as instabilidades do momento, assim como as incertezas do porvir; precisa, acima de tudo, acolher a vida e as constantes surpresas que esta pode apresentar; e, acolher o diferente e o aleatório como uma constante fonte de crescimento, renovação e (re)organização.

Os cuidadores de enfermagem devem, em suma, estar conscientes das formas peculiares de sentir e perceber a criança institucionalizada com aids, valorizando o ser ao fazer; o indivíduo à doença; e, a vida à morte.

\section{REFERÊNCIAS}

1. Schaurich D, Medeiros HMF, Motta MGC. Vulnerabilidades no viver de crianças com aids. Rev Enferm UERJ. 2007 Abr-Jun; 15(2):284-90.

2. Schaurich D, Padoin SMM. Ser mulher cuidadora de criança com aids: compreensões existenciais à luz da filosofia de Buber. Texto Contexto Enferm. 2008 Jul-Set; 17(3):569-77.

3. UNAIDS. Situação da epidemia mundial de aids. [online]. 2008 [acesso 2010 Jan 22]. Disponível em: http://www.onu-brasil.org.br/doc/ SumarioprincipaisdadosUNAIDS

4. Ministério da Saúde (BR). Resposta positiva 2008. A experiência do programa brasileiro de DST e AIDS do Ministério da Saúde [online]. Brasília (DF): MS; 2008 [acesso 2010 Jan 18]. Disponível em: http://www. aids.gov.br/portalaids_services/data/documents / storedDocuments / \% 7BB8EF5DAF-23AE-4891AD36-1903553A3174\%7D/\%7B54F4CD1A-C79043C5-8EBB-2E03686553B0\%7D/notas \%20junho\%20 2008\%20final.pdf

5. Falcon GCS, Erdmann AL, Backes DS. Significados do cuidar na promoção da saúde. Rev Latino-am Enfermagem. Mai-Jun 2008; 16(3):419-24.

6. Morin E. A cabeça bem feita: reformar a reforma reforça o pensamento. $10^{\mathrm{a}}$ ed. Rio de Janeiro (RJ): Bertrand Brasil; 2004. 
7. Strauss A, Corbin J. Pesquisa qualitativa: técnicas e procedimentos para o desenvolvimento de teoria fundamentada. $2^{\mathrm{a}}$ ed. Porto Alegre (RS): Artmed; 2008.

8. Minayo MCS. O desafio do conhecimento: pesquisa qualitativa em saúde. $8^{a}$ ed. São Paulo (SP): Hucitec, 2004.

9. Ministério da Saúde (BR), Conselho Nacional de Saúde, Comissão Nacional de Ética em Pesquisa. Resolução n196 de 10 de outubro de 1996: diretrizes e normas regulamentadoras de pesquisa envolvendo seres humanos. Brasília (DF): MS; 1996.

10. Medeiros HMF, Motta MGC. Existir de crianças com aids em casa de apoio: compreensões à luz da enfermagem humanística. Rev Gaúcha Enferm. 2008 Set; 29(3):400-7.

11. Medeiros HMF, Motta MGC. As repercussões de viver em casa de apoio para a criança com Aids. In:
Paula CC, Padoin SMM, Schaurich D, organizadores. Aids: o que ainda há para ser dito? Santa Maria (RS): EDUFSM; 2007. p. 255-68.

12. Backes DS. Vislumbrando o cuidado de enfermagem como prática social empreendedora [tese]. Florianópolis (SC): Universidade Federal de Santa Catariana. Programa de Pós-graduação em Enfermagem; 2008.

13. Alexandre DT, Vieira ML. Relação de apego entre crianças institucionalizadas que vivem em situação de abrigo. Estudos Psicol. 2004 Mai-Ago; 9(2):207-17.

14. Paula CC, Schaurich D, Padoin SMM, Crossetti, MGO. O cuidado como encontro vivido e dialogado na Teoria de Enfermagem Humanística de Paterson e Zderad. Acta Paul Enf. 2004 Out-Dez; 17(4):425-31.

15. Falcon GCS, Erdmann AL, Backes DS. Significados do cuidar na promoção da saúde. Rev Latino-am Enfermagem. 2008 Mai-Jun; 16(3):419-24.
Correspondência: Hilda Maria Barbosa de Freitas Centro Universitário Franciscano - Curso de Enfermagem Rua dos Andradas, 1614 - Centro 97010-032 - Santa Maria, RS, Brasil E-mail: hildasame@gmail.com
Recebido em: 27 de janeiro de 2010 Aprovação final: 9 de julho de 2010 